\title{
Women's Level of Education and Its Effect on Domestic Violence in Rural Bangladesh
}

\author{
Sarah Marium \\ (Development Studies, Brac Development Institute, Brac University, Bangladesh)
}

\begin{abstract}
This paper explores the association between women's education and domestic violence against women perpetrated by their husbands and in-laws in the context of rural Bangladesh. The aim of the study is to find out whether a low level of women's education has a causal relation with domestic violence in rural Bangladesh. The research has been conducted through analyzing primary researches and data on domestic violence and associated factors of violence in recent years. The study reveals that the contextual variation of a number of factors associated with domestic violence allows us to identify a correlation of education level of women with domestic violence. The paper concludes with the suggestion that providing women with higher level of education may present an environment for lower level of violence and women's autonomy. However, it also may indirectly intensify family violence, depending on the circumstance.
\end{abstract}

Keyword: Domestic Violence, Rural Bangladesh, Women's Educational Level, Women's Status

\section{Introduction}

Domestic violence against women has been a rising global concern because it is recognized as a worldwide phenomenon crossing the boundaries of countries, cultures, religions, and social or economic spheres. The developing countries of the world have a relatively higher number of women than the developed countries experiencing domestic violence by their intimate partners and in-laws (Naved and Persson, 2005). Among them, Bangladesh reports one of the highest records of domestic violence as between fifteen to fifty two percent of ever married women reported that they had been tortured by their spouse (Naved and Persson, 2005). Domestic violence is a burning issue of research in studies related to gender and equity, development studies, women's empowerment and human rights. Violence against women has severe physical and mental consequences, and thus, it is increasingly treated as a threat to human rights. According to researchers, just under half of all household deaths of women are due to ruthless beating by their husbands (Ahmed, 2005). Based on empirical studies conducted in recent decades, the paper explores the factors that correlate with domestic violence in rural Bangladesh. Dowry payments and early marriage, men's low educational level, poverty, gender norms and social beliefs, and other patriarchal constraints are some of the root causes of domestic violence. Besides these factors, low education level of women is an important factor that correlates with domestic violence. Therefore, this paper seeks to explore if and how low level of women's education is an important factor associated with household violence, specifically in a rural context of Bangladesh. The research is based on the work conducted by scholars and development agencies, such as the WHO, UNDP. First, the paper discusses some of the common forms of domestic violence. Second, it shows the situation of other developing countries regarding low level of education and violence. After that, some statistical data from recent years on domestic violence have been illustrated to show the relation of domestic violence and education level of women. Next, the paper explores how the occurrence of domestic violence in both cases of educated and uneducated women is highly influenced by contextual factors, such as, poverty, dowry, women's bargaining power, Nation's education level, husband's education level, community factors, gender norms, girls' age during marriage, socialization of girls and boys etc. Afterward, the incidence of silent victims is analyzed from social context. Eventually, an overall analysis and conclusion of the paper is presented.

\section{Common forms of domestic violence}

Domestic violence refers to coercive and aggressive behavior of adults or adolescents against their intimate partners (WHO, 2005). The violence includes methodical use of threats, exploitation, and physical violence, sexual, verbal, and psychological attacks (WHO, 2005). Through these strategies of violence, abusers aim to implant fear in and dominate over their partners and to take control over the family environment (Naripokkho and Bangladesh Mahila Parishad, n.d). The abusive partners, especially men, seek to achieve certain pattern of behaviors from their wives through violence. Some common forms of domestic violence against women include hitting with fists, punching, pushing, kicking, acid throwing, beating, murder, marital rape etc (Naripokkho and Bangladesh Mahila Parishad, n.d). 


\section{Low Literacy Rate and Domestic Violence in Developing Countries}

Generally, it is assumed that a low literacy rate of women contributes as an important factor of domestic violence. As uneducated women are economically less productive, it is typically the case that they are seen to have a less bargaining power in the family. (Arends-Kuenning and Amin, 2001). Therefore, they are inferior in position to their husbands. Although lower status and less bargaining power of women due to low level of education is a common scenario among other developing countries such as India, Pakistan etc., this paper particularly explores the relationship with educational level of women and domestic violence in the context of rural Bangladesh (Niaz, 2003). Comparative analysis of developing countries of Asia, Africa and Middle East reveals the similarity that rigid cultures and patriarchal norms devalue the role of women and constrain women's basic right to education which may eventually result into the occurrence of domestic violence (Niaz 2003; Kimani 2007 and Hajjar 2006). It could be assumed that greater years of schooling may provide women with an opportunity to gain knowledge and information which they often lack and as a result become less vulnerable (Arends-Kuenning and Amin, 2001). The latter portion of the paper presents the research and analysis of how women's educational level relates to the incidence of domestic violence.

\section{Statistical Data of Literacy Rate and Family Violence}

According to statistical data, in rural Bangladesh during 2000-20002, female adult literacy rate was 43.2\% (General Economics Division and UNDP Bangladesh, 2007). In 2004, it increased into $45.8 \%$ and in 2005 it further improved to 47.9\% (General Economics Division and UNDP Bangladesh, 2007). Therefore, statistical data shows an increasing level of women's education in Bangladesh. However, reported incidents of violence against women for dowry in police stations was 274 in 2001-2002 and in 2002-2004 time period it was increased in a total of 832 cases (Farouk, 2005). Additionally, from 2001-2004, the reported cases of rape also increased from 228 to 291 (Farouk, 2005). The statistics provide an overall picture of Bangladesh. These studies show that, even though women literacy rate is increasing, family violence is not decreasing, but increasing with time. So it indicates that improving the educational level of women might not correlate with a decline in domestic violence. However, these statistics only show some of the reported cases. Much household violence for dowry, including other cases, for example, murder, marital rape, beating are not reported to the police due to patriarchal constraints (Farouk, 2005).

\section{Dowry, Education and Domestic Violence}

Next, a context specific study accomplished in 2001, in three districts of Bangladesh explored whether educational level of women and dowry payments are interrelated, and if so, what the amount of dowry was for an educated and an uneducated bride (Amin, 2008). As dowry demand often associates domestic violence, the study can be used to explore the relation between educational level, dowry and domestic violence. The results revealed an interesting variation on the education-dowry relationship: generally, education has a positive impact on girls for they possess a stronger position in the society (Amin, 2008). They are considerably more likely to marry without paying dowry. However, due to higher social status of a highly educated bride, the bride has to pay a considerably higher amount of dowry (Amin, 2008). In this regard, the social status allows her to pay a higher amount of dowry. In this regard, the parents of the bride's family have less or no control over the situation because often they have to meet the social expectations. On the other hand, payment of dowry were generally small for the girls who did not receive education, but these girls share a larger proportion among the total number of women who pay dowry (Amin, 2008). This pattern suggests that schooling, marriage strategies, amount of dowry are related to each other (Huq and Amin, 2001; Suran, Amin, Huq, and Chowdhury 2004 in Amin 2008). Domestic violence was lowest among the educated women who did not pay any dowry at all. Moreover, the highly educated women who paid a substantially higher amount of dowry during marriage, dowry demand increased with time and incidence of domestic violence only decreased if the bride's family was able to fulfill the demand (Amin, 2008). Thus, the relative variation in social factors increases or decreases domestic violence in the society and educational level of women is not the only determinant to decrease family violence.

\section{Women's Bargaining Power, Educational level and Domestic Violence}

Women's bargaining power is also another factor associated with domestic violence. The bride's weak bargaining position is determined through her weak physical, economic, or social position. The qualitative data strongly suggest that beauty, health, sexual purity, family status, and good social networks assists the bride's family to find a good match for the girl in marriage market (Suran, Amin, Huq, and Chowdhury 2004; Amin and Suran 2005 in Amin 2008). Education can improve the chance of a good marriage because educated girls enjoy a better health, have the potential to give birth to a healthy child and can build a strong social network (Amin, 2008). However, education does not inherently associate with the family status or beauty of a girl. As a result, even though a girl is educated she might be charged to pay a higher amount of dowry due to her dark complexion and have to tolerate brutal abuse if she is unable to meet the dowry demand (Arends-Kuenning and 
Amin 2001 and Amin 2008). These factors are difficult to measure in surveys and remain part of the unexplained variation in the quantitative analysis of dowry and spousal abuse. However, education has the potential to offer a girl a variety of choices of selecting a life partner and in cases of marriages based on mutual understanding of the men and the women, usually, the dowry demands and family violence are not present (Huq and Amin, 2001; Suran, Amin, Huq, and Chowdhury 2004 in Amin 2008).

\section{Poverty, education of Women and domestic Violence}

Another survey was conducted in the Rajshahi division of Bangladesh, where dowry and early marriage are both highly common; this survey aimed to explore the connection between girls' education and dowry demands (Amin, 2008). In rural Bangladesh, girls who complete secondary level get a national secondary school scholarship for their attendance (Arends-Kuenning and Amin, 2001). This incentive program decreased the gender gap in schooling. Researchers assessed whether the girl's schooling has a positive outcome associated with dowry. But, they did not find significant evidence to show a relationship with dowry (Amin, 2008). However, a girl's schooling has an impact on her spousal relationship because the communication gap between the husband and the wife narrows as a result of improved gender equity (Huq and Amin 2001 in Amin 2008). Therefore, increased spousal communication appears to lead to less domestic violence. However, if the girl's natal and marital families suffer from severe poverty, then, even if she receives education up to secondary level and has gender equity in terms of human rights, impoverishment indicates lower empowerment of the women and in this situation of dowry demand becomes prevalent (Amin, 2008). As the poor marital family of the girl likely values money above all her qualities, dowry demands along with physical and mental abuse grows recurrently.

\section{Husband's level of education and domestic violence}

A husband's level of education is protective against domestic violence in rural sites only if the husband obtained education much higher than the secondary level (Naved and Persson, 2005). Husbands' high educational attainment tends to protect women from violence because it helps to fight the conventional gender norms which are very strong in rural areas (Naved and Persson, 2005). Moreover, if husbands are well educated, then they are tolerant, understanding and cooperative with their wives in many cases. Therefore, besides women's education, male education is an important indicator to reduce domestic violence.

\section{Nation's Educational Level and Domestic Violence}

In comparative analysis of reports of physical and sexual violence a nation's educational level has a significant role to play, according to a report of WHO on domestic violence against women (WHO, 2005). Comparison between Japan and Bangladesh contributes to understand that the national educational level along with higher individual level of education is both necessary to reduce violence (WHO, 2005). The WHO report contends that a reduction of violence is possible when women receive education beyond secondary level which results into a relatively late marriage than an uneducated girl reducing the educated girl's vulnerable position in the in-laws house, increased autonomy and control of resources though greater earning capacity (WHO, 2005). Therefore, the analytical view of this report portrays the importance of a higher level of adult literacy rate and mean years of schooling. However, according to the report, a fair section of women in rural Bangladesh believe that their husbands have right to abuse them. Thus, considering violence against women as a "normal" and socially acceptable behavior of men, women remain in a prolonged violent relationship (WHO, 2005). Thus, even if girls receive education, reduction of domestic violence might not be possible because of socialization of girl in a particular social setting. Hence, it is obvious that education might or might not reduce violence implying that education is an important determinant of domestic violence but it may be associated with many other factors resulting into either decrease or no decrease in occurrence of the violence. Therefore, social norm and belief are influential indicators which specify the occurrence of violence against women.

\section{Women's Education, Contatextual Factors And Violence}

As opposed to gender norm and social belief, overall gender equality in the community might provide tortured women with better alternatives and, provide an option of leaving the husband's house during severe marital conflicts and violence (Amy and Jill, n.d). For example, women's threat of leaving a house is more credible if women in the community are engaged in different income earning activities and their wage rate is high leading to a high decline in marital violence rate. In this context too, women's education is reaffirmed because educated women are more capable then a less educated women in using technological and social resources, are aware of gender equality and social networking and benefit from a sufficient amount of wage (Naved and Persson, 2005). Along with their rising wage, the incidence of domestic violence decreases. Therefore, education is inversely related to domestic violence if community factors are favorable for women. In 
this circumstance, education is interrelated with other contextual community factors, and the community factors play an important role in decreasing domestic violence in an educated women's life.

\section{Women's Earning Capacity and Challenging Gender Norms}

Although, women's saving and credit groups have become popular within the rural Bangladesh, women's participation in saving and microcredit group has been controversial (Schuler et al, 1996). It depends upon social setting and context whether their participation in credit programs will be appreciated or not. Women's participation in micro-credit group has a varied impact on domestic violence against women (Schuler et al, 1996). As the society of Bangladesh is conservative, women's participation in credit programs is still not gladly accepted. Therefore, even small increase in personal income might increase the violence in the family as it is perceived as challenging conventional social norms, which has an impact on the increase the risk of domestic violence (Naved and Persson, 2005). However, if women are capable of earning a substantially large amount of money after receiving a higher level of education and having better access to resources of credit and micro-finance groups, then they are at lower risk of domestic violence because they enjoy increased control in family decision through larger contribution in total family income (Naved and Persson, 2005). However, an opposite picture of increased violence can be portrayed if men assert that higher income of female than male decreases men's masculinity (Ahmed, 2008). Research shows that some men perceive that their status as family provider has been demolished through higher capacity of income of their wives; therefore they attempt to take violent steps to regain their power (Ahmed 2008, White 2007). Using domestic violence for gaining control over women is a typical stereotypical idea of men's masculinity (Dean, 2005). So, if men respond to increased income of women by lowering the incidence of domestic violence, women might decide to stay in the relationship. The contextual variation of a number of factors reveals that the promotion of women's position through education and earning capability in the family might or might not decrease the family violence.

\section{Bride's age and educational level and family violence}

Studies show that women's relative age is an important risk factor of domestic abuse (Suitor et al. 1990; Bachman et al.1995; Schuler et al. 1996; Haj-Yahia 2000; Black et al. 1999 in Naved and Persson, 2005). In Bangladesh most girls enter marriages in their teens. Their status as young wives is usually low (Koenig et al, 2003). According to patriarchal norm they start their marriage life in their husband's family's home. At that new family setting young women have less status and therefore are at high risk of domestic violence relative to women who are older (Koenig et al,1998). This indicates the importance of girl's schooling and getting married at 18 or after 18 so that they can achieve the higher secondary level education which can ensure their better status in in-laws home and helps to perform traditional and economic role (Arends-Kuenning and Amin, 2001). A girl, who has passed her higher secondary level with a substantial earning capacity, can experience lower violence. In this case, her maturity, income level and education works together to provide her a safe environment in marriage. Therefore, education can mitigate the influence of other risk factors associated with domestic violence.

\section{Socialization of Girls and Boys and Violence}

According to studies, the occurrence of domestic violence is common among adults who had experienced physical and mental abuse during their young age (Sugarman and Hotaling 1989). They perceive violence as a behavior to tackle a conflict situation (Sugarman and Hotaling 1989). Another related reason might result from the observation of domestic violence in the family during childhood and therefore, the learned aggressive behavior from a family role model reflects in the character in later life (Naved and Persson, 2005). For example, a boy observing his father abusing his mother is more likely to behave aggressively towards his wife during his adult hood. Similarly, a girl might learn to be submissive to domestic violence if she observes her mother to be passive and silently bearing tortures (Naved and Persson, 2005).

\section{Analysis of Frequency of Silent Victims}

Questions arise as to why many victims continue to stay with abusive spouses and are silent and do not speak out. First, in Bangladesh the social context in which women are raised are from an early age, taught to be submissive, tolerant, and self-sacrificing (Farouk, 2005). Furthermore, the biased social belief that a woman's place is in her in-law's home is also entrenched in women's mentality. The social value places women into a complex situation to claim themselves and protest against domestic violence (Farouk, 2005). In cases of marital and family conflict, society exclusively puts the blame on women and holds her accountable for her failure of not being able to build strong foundation in the family, not able to maintain peace and not being tolerant within family environment (Farouk, 2005). Consequently, women are reluctant to complain of domestic violence or file cases against their husbands because they fear social stigmatization. Another reason that women rarely assert themselves is that women have few alternatives to live elsewhere rather than their husband's home (Farouk, 
2005). In some contexts, a woman might return to her natal family but society will not support her. Therefore, with little choice existing, women continue to live in their husband's home even there are incidences of domestic violence.

\section{Overall Analysis}

Overall analysis of the paper suggests that determinants of domestic violence are a combination of community level factors with household and individual level factors. Instead of showing causal relation these factors have strong correlations among themselves affecting women's autonomy, empowerment, gender relation and domestic violence. The causes of domestic violence are very context specific. Moreover, because several variables work at the same time to increase or decrease the level of domestic violence, therefore identifying the major determinant becomes very difficult. In addition, women's empowerment, education and autonomy do not necessarily mitigate the level of domestic violence in all community or individual levels. Rather, these factors varies significantly in different socioeconomic context revealing a multifaceted association between women's education and domestic violence with different other dominant variables, for example, gender relation, poverty, social norms, dowry, women's economic contribution present in the background. Thus, we cannot conclude that lower rate of education is causing domestic violence. Although, higher women's education is certainly an important indicator to reduce violence against women, the complicated social structural impedes us from identifying low educational level of women as the only cause of domestic violence.

\section{Conclusion}

Despite the severe physical and emotional health consequences of women, domestic violence is not recognized as a serious social problem and society does not identify domestic violence to be a serious crime. Rather, it is viewed as a personal matter that should be resolved privately within the family (Naripokkho and Bangladesh Mahila Parishad, n.d). The male members of the family dominate and forcefully suppress women not to speak against them. As a result, generally, law enforcement agencies are unwilling to get concerned in cases of domestic violence and women are often mistreated without any choice (Farouk, 2005). As society accepts male domination in the family men take the advantage of this notion and use their authority to torture women. Moreover, women's tolerance of domestic violence further establishes domestic violence in the society of Bangladesh. Education can play an important role in demolishing the negative social norms that cause women to be oppressed; however other social and community factors which reduce domestic violence should be reconciled with education to maintain a favorable family and social environment for women to achieve women empowerment.

References

[1]. Ahmed, S. M. (2005). Intimate Partner Violence against Women: Experiences from a Woman-focused Development Programme in Matlab, Bangladesh. The Journal of Health, Population and Nutritio, 23(1), 95-101. Retrieved from http://www.bioline.org.br/request?hn05011

[2]. World Health Organization. (2005). WHO Multi-country Study on Women's Health and Domestic Violence against Women. Retrieved from http://www.who.int/gender/violence/who_multicountry_study/summary_report/summary_report_English2. pdf

[3]. Naripokkho and Bangladesh Mahila Parishad. (n.d). Baseline Report: Violence against Women in Bangladesh. Retrieved from http://www.iwraw-ap.org/aboutus/pdf/FPvaw.pdf

[4]. Arends-Kuenning, M. \& Amin, S. (2001). Women's Capabilities and the Right to Education in Bangladesh. International Journal of Politics, Culture, and Society, 15(1), 125-142. Retrieved from http://www.jstor.org/stable/20000178?seq=2

[5]. Amin, S. (2008). Reforming Marriage Practices in Bangladesh. Promoting Healthy, Safe and Productive Transitions to Adulthood. Retrieved fromhttp://www.popcouncil.org/pdfs/TABriefs/PGY_Brief31_MarriageBangladesh.pdf

[6]. Niaz, U. (2003). Violence against Women in South Asian Countries. Archives of Women's Mental Health, 6(3), 173-184. Retrieved from http://jthomasniu.org/class/781/Assigs/nias-violwom.pdf

[7]. Kimani, M. (2007). Taking on Violence against Women in Africa. Africa Renewal, 21(2), 4. Retrieved from http://www.un.org/en/africarenewal/vol21no2/212-violence-aganist-women.html

[8]. Hajjar, L. (2006). Religion, State Power, and Domestic Violence in Muslim Societies: A framework for Comparative Analysis. Law and Social Inquiry, 29(1). Retrieved from http://onlinelibrary.wiley.com/doi/10.1111/j.1747-4469.2004.tb00329.x/pdf

[9]. General Economics Division, Planning Commission, Government of the People's Republic of Bangladesh \& UNDP Bangladesh. (2007). A Situation Analysis Report on Gender (MDG 3) Bangladesh. Retrieved from http://www.undp.org.bd/projects/prodocs/PRS_MDG/Situation\%20analysis_GENDER.pdf

[10]. Farouk, S. A. (2005). Violence against Women: A Statistical Overview, Challenges and Gaps in Data Collection and Methodology and Approaches for Overcoming Them. Bangladesh National Women Lawyers Association. Retrieved from http://www.un.org/womenwatch/daw/egm/vaw-stat-2005/docs/expert-papers/Farouk.pdf

[11]. Naved, R. T., and Persson, L. A. (2005). Factors associated with spousal physical violence against women in Bangladesh. Studies in Family Planning, 36(4), 289-300.

[12]. Amy F. \& Jill T. (n.d). Explaining the Recent Decline in Domestic Violence. Retrieved http://www.nasams.org/DMS/Documents/1195248210.25/Explaining\%20Decline\%20in\%20Domestic\%20Violence.pdf

[13]. Schuler, S. R., Hashemi, S. M., \& Badal, S. H. (1998). Men's violence against women in rural Bangladesh: undermined or exacerbated by microcredit programmes? Development in Practice, 8(2), 148-157. Retrieved from http://www.jstor.org/stable/pdfplus/4029300.pdf?acceptTC=true 
[14]. Ahmed, F. E. (2008). Microcredit, Men, and Masculinity. Feminist Formations, 20 (2), 122-155. Retrieved from http://www.bupedu.com/lms/admin/45ploaded_article/A.18.pdf

[15]. White, S. C. (1997). Men, Masculinity, and the Politics of Development. Gender and Development, 5(2), 14-22. Retrieved from http://www.jstor.org/stable/4030435

[16]. Dean, L. L. (2005). The Construction of Masculinity and the Roots of Domestic Violence as Seen Accounts of Battered Women. Retrieved from http://www.warwilson.edu/ socanth/students/Dean05.htm

[17]. Koenig, M. A., Ahmed, S., Hossain, M. B \& Mozumder, A. B. M. K. A. (2003). Women's Status and Domestic Violence in Rural Bangladesh: Individual- and Community-Level Effects. Demography, 40 (2), 269-288. Retrieved from http://www.jstor.org/stable/10.2307/3180801

[18]. Koenig, M., Hossain M. B., Ahmed, S. \& Haaga, J. (1998). Individual and Community Level Determinants of Domestic Violence in Rural Bangladesh. Retrieved from https://jscholarship.library.jhu.edu/bitstream/handle/1774.2/969/WP99-04.pdf?sequence=1

[19]. Sugarman, D.B. \& Hotaling G.T. (1989). Violent Men in Intimate Relationships: An Analysis of Risk Markers. Journal of Applied Social Psychology, 19, 1034-1,048. doi: 10.1111/j.1559-1816.1989.tb01237.x 